\title{
Modern comprehensive approach to monitor the morphodynamic evolution of a restored river corridor
}

\author{
N. Pasquale ${ }^{1}$, P. Perona ${ }^{1,2}$, P. Schneider ${ }^{3}$, J. Shrestha ${ }^{4}$, A. Wombacher ${ }^{5}$, and P. Burlando ${ }^{1}$ \\ ${ }^{1}$ Institute of Env. Engineering, ETH Zurich, Zurich, Switzerland \\ ${ }^{2}$ Group of Applied HydroEconomics and Alpine environmental Dynamics, Institute of Environmental Engineering, \\ EPFL-ENAC, Lausanne, Switzerland \\ ${ }^{3}$ EAWAG, Swiss Federal Institute of Aquatic Science and Technology, Duebendorf, Switzerland \\ ${ }^{4}$ WSL, Swiss Federal Institute for Forest, Snow and Landscape Research, Birmensdorf, Switzerland \\ ${ }^{5}$ Dept. of computer Sciences, University of Twente, Twente, The Netherlands
}

Received: 27 October 2010 - Published in Hydrol. Earth Syst. Sci. Discuss.: 16 November 2010

Revised: 22 March 2011 - Accepted: 25 March 2011 - Published: 8 April 2011

\begin{abstract}
River restoration has become a common measure to repair anthropogenically-induced alteration of fluvial ecosystems. The inherent complexity of ecohydrologic systems leads to limitations in understanding the response of such systems to restoration over time. Therefore, a significant effort has been dedicated in the recent years worldwide to document the efficiency of restoration actions and to produce new effective guidelines that may help overcoming existing deficiencies. At the same time little attention was paid to illustrate the reasons and the use of certain monitoring and experimental techniques in spite of others, or in relation to the specific ecohydrologic process being investigated. The purpose of this paper is to enrich efforts in this direction by presenting the framework of experimental activities and the related experimental setup that we designed and installed in order to accomplish some of the research tasks of the multidisciplinary scientific project RECORD (Restored Corridor Dynamics). Therein, we studied the morphodynamic evolution of the restored reach of the River Thur near Niederneunforn (Switzerland), also in relation to the role of pioneer vegetation roots in stabilizing the alluvial sediment. In this work we describe the methodology chosen for monitoring the river morphodynamics, the dynamics of riparian and of in-bed vegetation and their mutual interactions, as well as the need of complementing such observations with experiments and with the hydraulic modeling of the site. We also discuss how the designed installation and the experiments
\end{abstract}

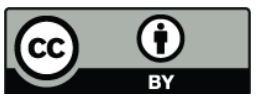

Correspondence to: N. Pasquale (nicola.pasquale@ifu.baug.ethz.ch) integrate with the needs of other research groups within the project, in particular providing data for a number of investigations thereby including surface water and groundwater interactions, soil moisture and vegetation dynamics.

\section{Introduction}

In the past century the main streams of many rivers have been straightened and channelized worldwide for both hydraulic and socio-economic reasons such as, for instance, flood protection, land use changes, agriculture or spreading of infectious diseases (Lacey, 1930; Inglis, 1949; Brookes, 1988). However, later it has become clear that such corrections affect considerably the associated riverine ecosystem, which typically reacts to artificial perturbations on multiple time scales (Malmqvist and Rundle, 2002; Tockner and Stanford, 2002). For instance, straightening the main water course affects both the river sediment dynamics and the lateral exchanges and connectivity with the floodplain on short temporal scales (e.g., weeks), whereas morphological changes and the related effects in habitat availability and in local biodiversity occur over longer temporal scales (e.g., months, years). In the last decade, many projects of river restoration have been initiated in order to bring local sections of rivers back to an improved natural appearance and thus to partially remediate to the consequences of large scale river straightening.

River bed and floodplain morphologies play a big roles in determining the lateral connectivity between the main stream dynamics and the moisture condition of the side terraces, which are critical for the ecotone development. Thus,

Published by Copernicus Publications on behalf of the European Geosciences Union. 
forcing changes of river bed morphology by either artificial or natural widening actions is one of the most common restoration techniques for those rivers that in origin showed a braided morphology (Formann et al., 2004; Peter et al., 2006; Schweizer, 2007). Restoration is usually intended as "the complete structural and functional return of the river to a predisturbance state" (Cairns, 1991). Soar and Thorne (2001) notice that full-restoration to a pre-disturbance state is an ideal concept. Hence, in the context of this paper, we define river restoration as "the input actions that serve to trigger the fluvial ecosystem evolution toward a new self-sustaining statistical equilibrium (if existing)" (Wohl et al., 2005). Following the initiation of restoration, it is also important to address the question of quantifying its success (Peter et al., 2006; Palmer et al., 2010), especially as far as coupled hydroecological processes are concerned (M. Schirmer, personal communication, 2010). In this respect, useful hydrologic and ecologic indicators have been developed to evaluate the present status of rivers (Woolsey et al., 2007). However today's literature about river restoration mostly deals with practical guidelines that have gradually been built on results, observations and lessons learnt by comparing pre- and immediate post restoration on case study (e.g., Mitsch, 2003). The literature is apparently missing systematic studies addressing an integrated mechanistic understanding of the evolution after restoration over longer time periods. Densmore and Karle (2009), for instance, recognize the value of long-term monitoring of restored streams.

In this descriptive paper we present the comprehensive framework of experimental activities that we adopted to monitor the evolution of the restored river corridor of the Thur River, near Altikon, in Switzerland. We illustrate our monitoring strategy to study the morphodynamic evolution of the restored river reach, particularly addressing the role of riverine vegetation. We describe the instrumentation and the facilities available in the project RECORD, the experiments carried out and both the hydraulic and morphodynamic modeling of the site. Since the project started in 2008, the instrumentation installed on the field has been providing data to support a mechanistic understanding of a number of fundamental processes linking flow, sediment and vegetation dynamics, also focusing on the role of root mechanical anchoring in stabilizing non-cohesive alluvial sediments. In order to show the research potential behind the collected data we also provide an essay of preliminary results.

The paper is organized as it follows: Sect. 2 gives a short overview about Thur River history and hydrology. Section 3 explains the need for a mechanistic understanding of restoration. Section 4 describes the field installation, materials and adopted methods. Examples of application of the installed instrumentation together with some first results are described in Sect. 5. A constructive discussion focusing future analysis concludes the work in Sect. 6.

\section{Thur River hydrology and history}

The Thur River is a perennial river in the north-eastern part of Switzerland (Fig. 1a and b). The catchment area is about $1750 \mathrm{~km}^{2}$ and the river has a length of about $127 \mathrm{~km}$. It is the longest river in Switzerland that flows continuously without any regulation by artificial reservoir or natural lakes. The hydrologic regime of the river is nivo-pluvial with the characteristic presence of flash floods. In spring and autumn flood pulses are created as a combination of snow melt and intense precipitation. Discharge may increase dramatically within a few hours and trig both bed load and suspended sediment transport.

The mean annual discharge (MQ) is $47 \mathrm{~m}^{3} \mathrm{~s}^{-1}$. Peak flows (HHQ) up to $1130 \mathrm{~m}^{3} \mathrm{~s}^{-1}$ have been observed, thus leading to a HHQ/MQ ratio of 24. Observed low flows can be as low as $2.2 \mathrm{~m}^{3} \mathrm{~s}^{-1}$.

Originally, the lower Thur River showed a clear braided morphology (Fig. 1c). Before the first half of the 20th century the river was channelized like most of the major rivers in Europe to avoid frequent flooding and gain arable land. Such first river correction basically transformed the floodplain into a double trapezoidal channel with a $45 \mathrm{~m}$ wide low-water channel (flow capacity $230 \mathrm{~m}^{3} \mathrm{~s}^{-1}$ ) with embankment and artificial floodplains (total flow capacity $1100 \mathrm{~m}^{3} \mathrm{~s}^{-1}$ ) confined within levees. Spacing between the levee crest was $160 \mathrm{~m}$ and the vertical distance between riverbed and levee crest averaged $6 \mathrm{~m}$. The failure of the levees during the large 1977 and 1978 floods 1977 and 1978 suggested to enlarge the floodplain between the levees in order to increase the channel conveyance capacity (today the low flow channel and the total flow capacities are about $300 \mathrm{~m}^{3} \mathrm{~s}^{-1}$ and $1300 \mathrm{~m}^{3} \mathrm{~s}^{-1}$, respectively) by removing fluvial deposits from the forelands between the levee (Fig. 1d). However, these corrections caused erosion of the river bed. This triggered the plan for a second Thur River correction, which had to consider both flood protection goals and the ecological status of the river. Since 1993 this correction equally promotes river restoration and flood protection measures. In 2002, a $2 \mathrm{~km}$ long section of River Thur near Neunforn/Altikon (see the box in Fig. 1b) was restored by completely removing the right side foreland, so that the nearby alluvial forest became part of the active floodplain again. Soon after the remodeling ended, the large widening forced the river to deposit sediments and to enhance the alternating bar patterns. Such pattern is the essential river attribute (Trush et al., 2000) that is fundamental for the creation of physical habitats for pioneer species (Fig. 1e and f). The restoration attempt had also a positive impact to mitigate the damages of flood events observed in the recent years. Following the successful correction and with the support of Universities, Research Centers, and the Zurich and Thurgau Cantonal Authorities, a comprehensive and multidisciplinary scientific project was funded in 2007 with the specific purpose of "Assessing and Modeling Coupled Ecological and Hydrological Dynamics in the Restored 

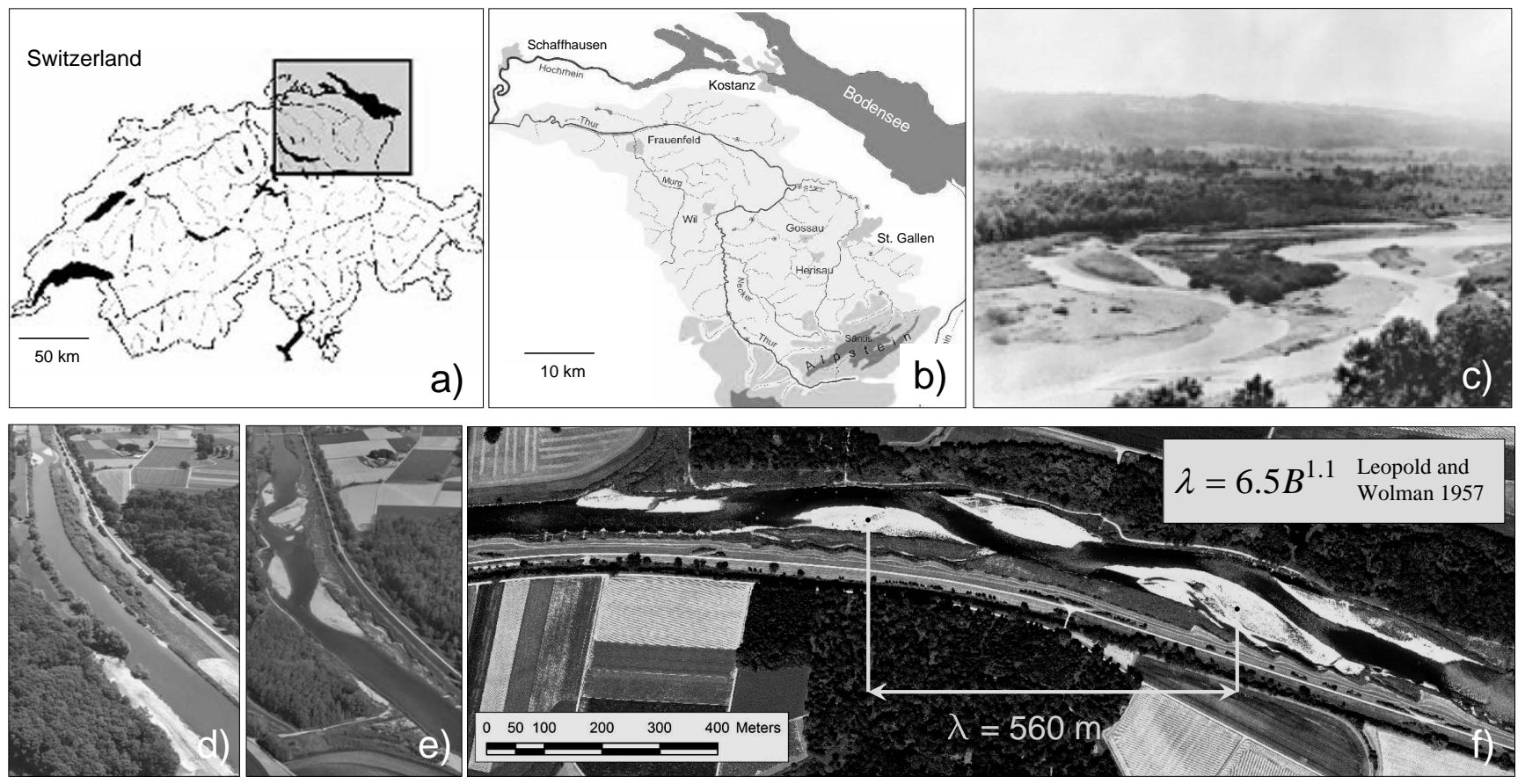

Fig. 1. Location of the river Thur in Switzerland (a) and river basin (b). From a natural braiding state (Rodhe, 2004) (c) the river was straightened (d) in the past century to improve flood protection, to increase agriculture areas and to reduce spreading of disease. As a consequence river bed faced serious erosion problems. After the restoration project started in 2002 the river naturally formed an alternate bar system (e, f).

Corridor (REstored COrridor Dynamics)" (Schirmer et al., 2011), which this study refers to.

\section{Science meets society: the need of a mechanistic understanding and research questions}

In order to construct the basis supporting the existence of mechanistic rules, we comment the aerial picture of the study area near Niederneunforn taken in 2005 (see Fig. 1f), i.e., soon after remodeling ended. The alternate bar configuration is a flow-sediment bedform instability well known in river mechanics (Ikeda et al., 1981; Colombini et al., 1987; Tubino and Seminara, 1990; Federici and Seminara, 2003). Compared to the bedforms observed in the non restored channel, river bars in the restored reach are larger and are submerged for flows $\left(250 \mathrm{~m}^{3} \mathrm{~s}^{-1}\right)$ much higher than the annual average (MQ). The natural formation of alternate bare bars and the formation of a diversity of habitats due to intense channel reworking with fast turnover rates attracted the scientific interest of ornithologists, ecologists, biologists, as well as the recreational sphere of local inhabitants. Among the somewhat unexpected results of this restoration action there is the return of the "Little Ringed Plover". This bird species preferentially breeds on bare or poorly vegetated alluvial sediment, and it visited the restored site after nearly 150 years from its disappearance from the region, i.e., from the time when the correction took place. This shows that the new river morphodynamics can control, even after relatively short time since restoration measure took place, the establishment of bird species that abandoned the river corridor after its channelization.

Apart from this interesting complementary success story, several other ecological and hydrological aspects, such as groundwater quality (Schneider et al., 2011), flood protection efficiency, long-term river morphology and biodiversity changes (Schirmer et al., 2011) are all eco-hydrological processes influenced by the new river hydraulics and morphodynamics. In this context an important research question concerns the understanding of the active (biological) role of vegetation (e.g., Jang and Shimizu, 2007; Gurnell and Petts, 2006; Nat et al., 2002) in relation to several other ecological and hydrological aspects, such as morphodynamics (Fig. 2a). Specifically, it is worth to investigate: (i) the morphologic changes of the restored reach in response to hydrologic disturbances, (ii) the interaction between flow, sediment and local vegetation, and (iii) the mechanical anchoring due to vegetation roots and its contributions to reach a dynamically stable restored river configuration (Fig. 2a).

A first quantitative analysis of the alternate bars pattern can be done by comparing the observed channel width with that predicted by both hydrodynamically-based (e.g., Ikeda et al., 1981; Federici and Seminara, 2003) or empiricallybased (Leopold and Wolman, 1957) relationships. For 

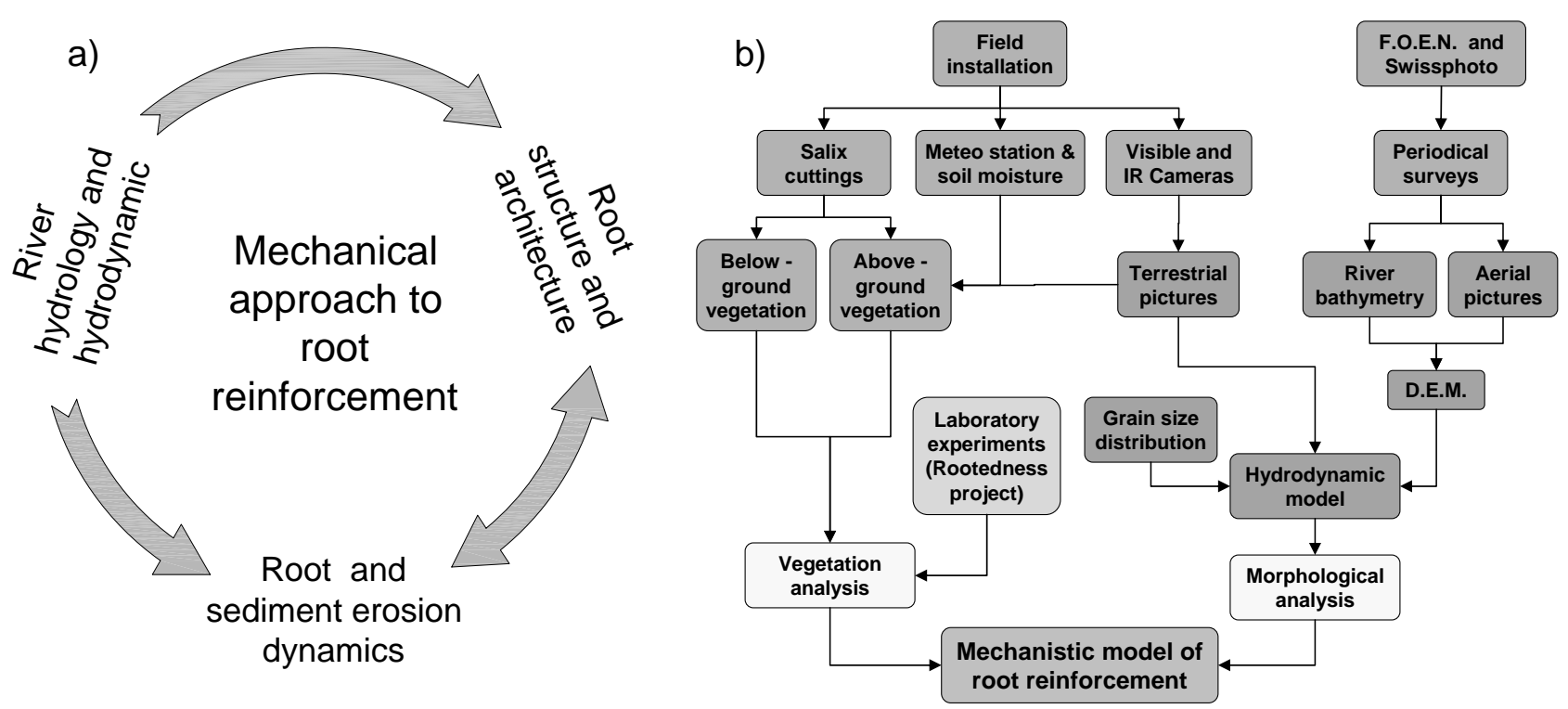

Fig. 2. Conceptualization of the interaction among river hydrology and hydrodynamics, root structure and architecture and sediment erosion and uprooting (a) and (b). Architecture of the investigation strategy to reach a mechanical understanding of root reinforcement (b).

instance the empirical equation proposed by Leopold and Wolman (1957) predicts the typical periodicity that characterizes such bedforms as

$\lambda=6.5 \cdot B^{1.1}$.

If we measure the curvilinear distance between bars on the aerial picture (Fig. 1f) we obtain $\lambda=560 \mathrm{~m}$, that yields from Eq. (1) $B=57 \mathrm{~m}$, which is approximately the average river width between the channelized and the restored reach. This is a first confirmation of the natural origin of the developed morphology. This development stage of the system seems also to suggest the tendency of the river to meander if lateral banks or levee would be exceeded. A first research question descends, which should address the influence of vegetation roots in controlling the movement of sediment, which, in turn, may limit the migration of alternate bars. Indeed, mechanical anchorage is one of the main functions of plant roots (Fitter, 1987) and it gives strong contribution to soil reinforcement (Pollen and Simon, 2005; Pollen, 2007; Millar, 2000).

A second research question concerns the amount of vegetation that can colonize the bare sediments. This is obviously related to the ability of the plant to anchor roots into the alluvial non-cohesive soil and to their resistance to flood drag and uprooting actions (e.g., Edmaier et al., 2011). Despite vegetation germinates on the bare sediment of the restored reach (see later sections), it does not seems to be able to colonize it. The gravel bars of the restored reach are still showing mainly grass and sporadic willow bushes about 6 years after the first restoration activities ended. Poorly vegetated sediment would in principle indicate a slow regeneration capacity as far as the creation of new terrestrial habitat is concerned.
Indeed the absence of vegetation cover limits fine sediment trapping, which represents a fundamental component of the hydrogeomorphic resilience and adjustment dynamics.

\section{Material and methods}

One of the naturally formed sedimentary island of the Thur River represents an almost ideal research area for the RECORD project in relation to the research questions identified in the previous section. The island is located in a slight bend of the river where the Thur flows through a rural area with many field crops and a riparian forest (Fig. 1f). The shape and size of such an island are obviously not constant, but changing in time because of erosion and aggradation induced by hydrodynamic forcing during floods. In order to capture the morphodynamic activity after restoration we adopt an active monitoring strategy summarized in Fig. 2b. The field installations consist of a meteorological station, soil moisture monitoring clusters (see Sect. 4.1), visible and near-infrared (NIR) cameras for terrestrial remote sensing (see Sect. 4.4) and three campaigns of Salix cuttings transplantation on the island (see Sect. 4.6). Since the beginning we have also taken advantage of the hydrological and topographic data provided by the Federal Office for the Environment (FOEN) and of aerial surveys, the latter being periodically updated on an annual basis. Meteo- and soil moisture station, jointly with observation of Salix (willow) cuttings evolution via direct and remote sensing carried out together with a parallel project (Edmaier et al., 2011) have been used for vegetation analysis. Topographic data such as river bathymetry (see Sect. 4.3) or digital elevation models 

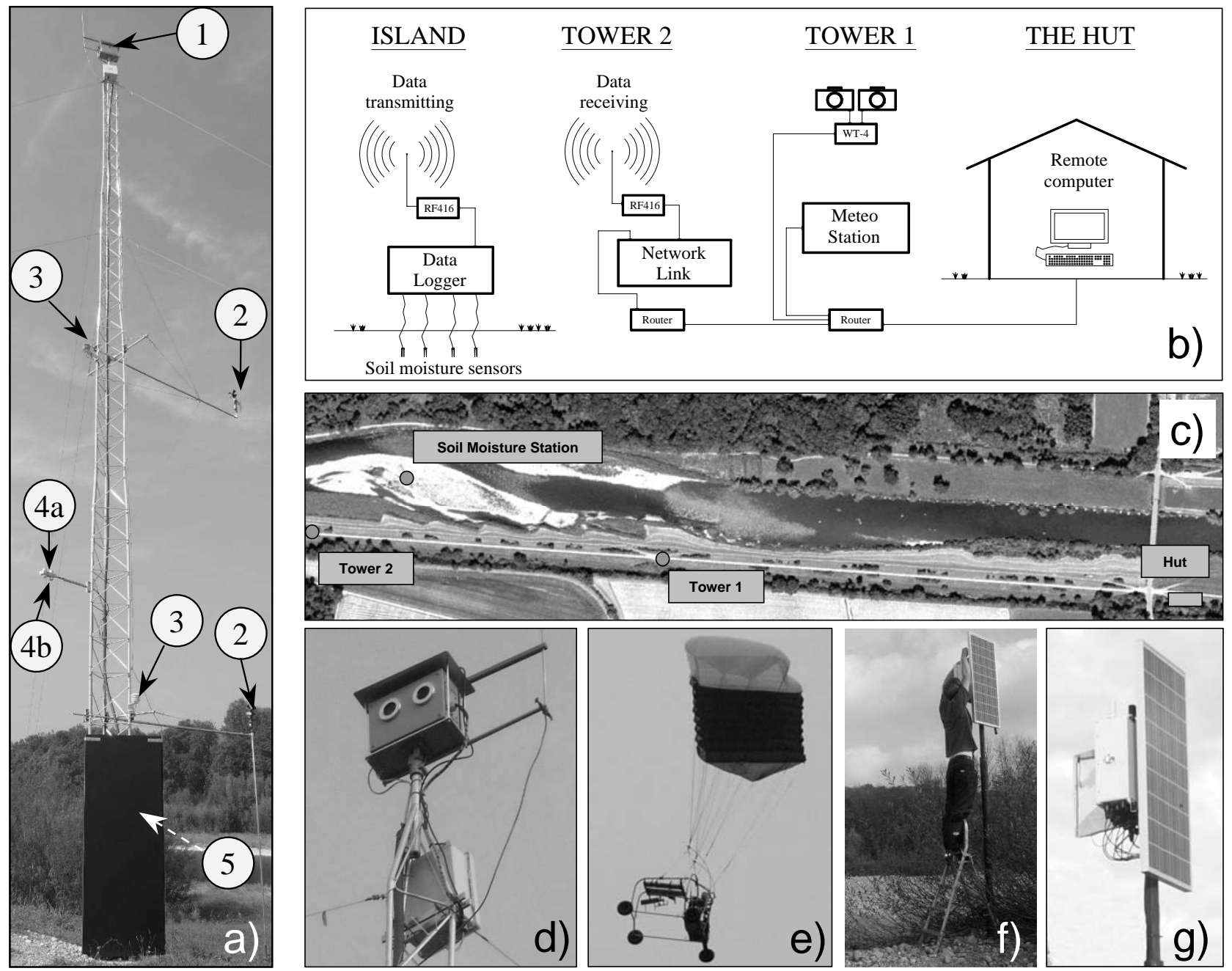

Fig. 3. Field installation: (a) shows the tower (Tower 1) with the meteorological station with the camera box (1,d), the two wind sensors (2), two temperature and relative humidity sensors (3), the incoming and reflected radiation sensors $(4 \mathrm{a}, \mathrm{b})$ and the pressure sensor (5). The soil moisture station on the island is wireless connected to the second tower on the levee. The second tower (Tower 2) has one box with two cameras and it is connected via optical wires to Tower 1 (b). The system is controlled by a computer located in a hut on the levee (b, c) and connected via optical fiber to Tower 1 (b). Picture (e) shows the motorized paraglider used for aerial pictures, whereas the soil moisture station on the island and a particular of the solar panel used to charge the data logger battery are shown in (f) and (g).

(DEMs) from aerial pictures, grain size distribution analysis (see Sect. 4.2) and hydrodynamic simulations (see Sect. 4.5) have been used for morphological analysis. Results from vegetation response to river hydrology and observations of morphological changes (Fig. 2a) will be later used to formulate a mechanistic model of non-cohesive soil reinforcement by roots (Fig. 2b).

\subsection{Local meteorological and soil moisture measurements}

In order to monitor the local meteorological variables necessary to compute a correct water balance at the reach scale we installed a complete meteo-station (Fig. 3a) on an aluminium frame tower (see Fig. 3a) located on the top of the left side levee (Fig. 3c). The higher position of the tower with respect to the river corridor allows for measurements to be representative of the mean local meteorology surrounding the restored reach. The meteo-station consists of recording raingauge, two sensor pairs measuring air temperature and relative humidity at $2.5 \mathrm{~m}$ and $8 \mathrm{~m}$ a.g.l. (above the ground level), a complete solar radiation device (i.e., measuring the four radiation at $4 \mathrm{~m}$ above the ground), two anemometers (also at $2.5 \mathrm{~m}$ and $8 \mathrm{~m}$ a.g.l.) and an atmospheric pressure sensor. The station is connected via optic fiber wires to a remote computer, located in a small hut about one kilometer upstream on the levee (Fig. $3 b$ and c). Thus, it is possible to remotely access the meteo-station, to download data 
in real time and eventually to reprogram the logger settings according to current needs. The installation includes also four soil moisture measuring spots installed on the island (Fig. 3f and g), which are wireless connected to a second tower (Fig. 3b). Each soil moisture sensor, based on capacitance technology, measures soil moisture and temperature at three different elevations $(20,40$ and $60 \mathrm{~cm})$ below the ground surface.

\subsection{Sediment size and nutrient spatial distribution}

Grain size distribution curves of the alluvial sediment forming the island have been obtained from six representative locations that were identified by simple visual survey (Fig. 4a). At each chosen location we took two samples, one at the surface and the second one about $40 \mathrm{~cm}$ underneath. Our purpose is to spatially identify and map sediment armoring and aggradation profiles (Lanzoni, 2000), as these control both sediment resistance to erosion and vegetation establishment. The two samples have been sieved to build grain size distributions, which are shown in Fig. $4 \mathrm{~b}$ and c. Generally, the sample taken at the surface (Fig. 4b) shows a higher percentage of coarse sediments than the sample at $40 \mathrm{~cm}$ depth (Fig. 4c). Moreover consistently with experimental observation reported by Lisle et al. (1991), Diplas and Parker (1992), Lisle and Madej (1992), Ashworth et al. (1992) the island is characterized by a longitudinal sorting. From coarse particle deposition upstream we move to fine sand deposition downstream (Lanzoni, 2000), where also stratification is not anymore evident. Successive visual observation have confirmed this pattern, leading us to assume that our grain size distribution is substantially independent from the macroscopic morphological changes of the island.

Sedimentation is the main source of fine materials and nutrients supply. Hence, soil texture, organic carbon and nutrient (nitrogen and phosphorus) contents in the lateral gravel bar upstream the island have been measured in the context of another scientific task of the RECORD project (BattleAguilar et al., 2011; Samaritani et al., 2010). In particular, six sampling plots have been taken on the right hand side bar (from 50 to $150 \mathrm{~m}$ upstream the island). As both the riverside bar and the island are formed by the same alluvial material, we assume that also the nutrient contents are similar. However, six additional samples have been taken from sparse location on the island inside the vegetation plots (see Sect. 4.6) to validate this assumption.

The collected soil samples have then been dried at $40^{\circ} \mathrm{C}$ and sieved at $2 \mathrm{~mm}$ for analysis of above-mentioned chemicals. The texture has been measured using the pipette method (Gee and Bauder, 1986). Organic carbon and total nitrogen have been measured in finely ground fine soils by using the method by Walthert et al. (2010). Available phosphorus has been measured colorimetrically by following the approach of Kuo (1996).
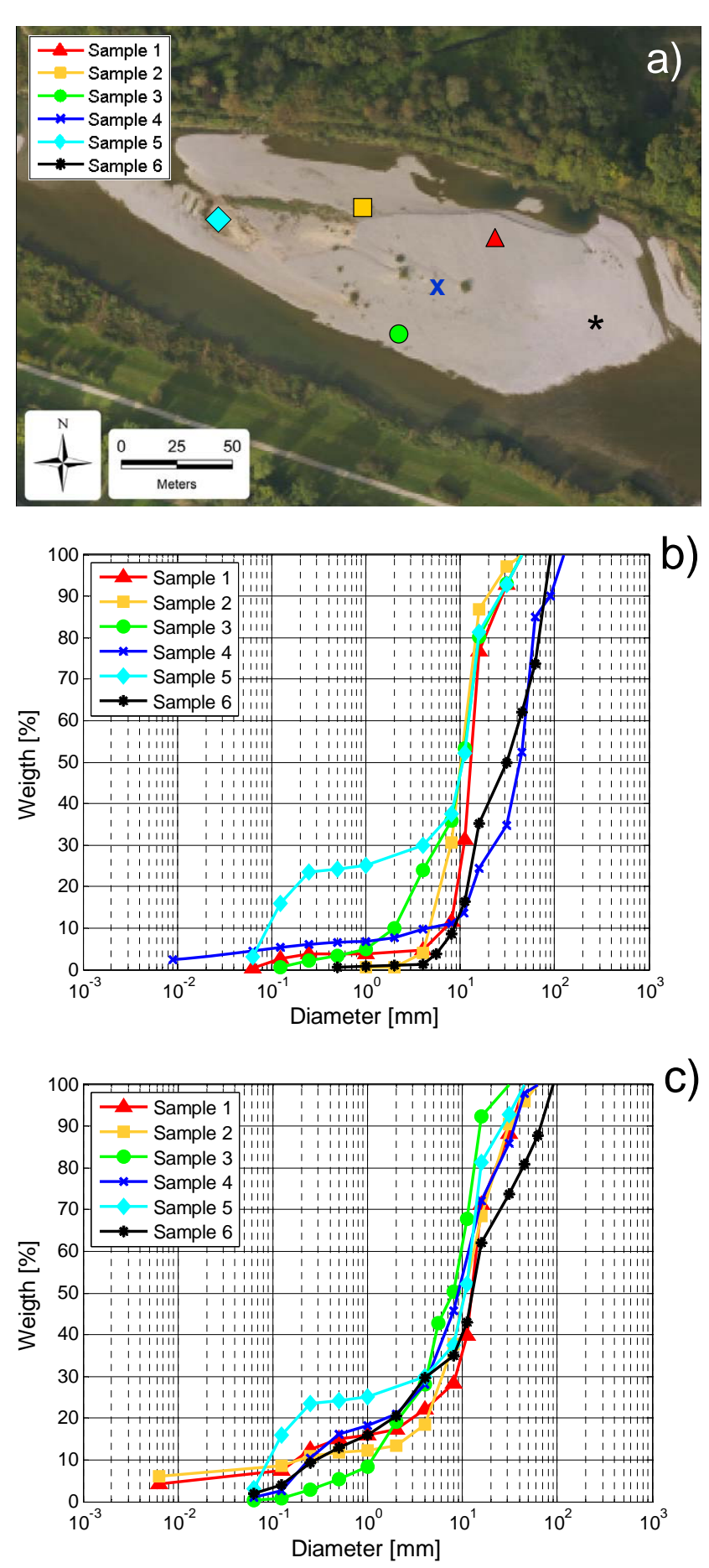

Fig. 4. Grain Size Distributions for the six different locations on the main island indicated in (a). Samples were taken on the surface (b) and at $40 \mathrm{~cm}$ depth (c). $d_{50}$ and $d_{90}$ are generally higher on surface layers (b) than at $40 \mathrm{~cm}$ (c). Surface samples (b) show also a higher spatial sediment sorting, from coarser material upstream (sample 6) to finer material downstream (sample 5). Sediment at $40 \mathrm{~cm}$ depth are more spatially similar and $d_{50}$ is practically equal for all samples (c). Comparing (c) and (d) it is evident the vertical sorting typical of river bed forms. 
Eventually, both the island and the lateral bar show a similar amount of nutrients, the statistics of which, averaged over the bar and the island, are reported in Table 1. The nutrient content in the gravel bar (with the exception of ammonium, which was quite uniformly distributed) is spatially variable, but does not follow any particular pattern. This suggests that differences in both quantity and quality of sediment deposition within the gravel bar are likely to occur. For instance, the organic carbon and nitrogen content is known to be strongly related to soil texture, whereas the quantity of sediment deposition is typically more important for phosphorus (Steiger and Gurnell, 2003). Although the nutrient content on the island is lower than in other part of the floodplain (data not reported here), its range is normal for sediment deposits of other large rivers in Europe (Steiger and Gurnell, 2003; Olde Venterink et al., 2006). Hence, as far as the gravel bars and island are concerned, we conclude that the nutrient content of the fine material is not the main limiting factor for plant growth. Elevation and grain size may both be more crucial than nutrient contents due to their control on soil water dynamics (Gilvear et al., 2008).

\subsection{Digital terrain model and river bathymetry}

An important element in hydraulic and morphodynamic modeling is the availability of detailed topographic data of the river bed and the floodplain area. The Federal Office for the Environment (FOEN), together with Canton Zurich and Canton Thurgau, provides detailed cross sections of the restored reach once a year. Surveys take place generally in late September-October. Summer season is characterized by the most important floods which are responsible of morphological changes. From annual LIDAR airborne flights, the corresponding Digital Terrain Model (DTM) is produced with a horizontal resolution $50 \mathrm{~cm}$ and vertical precision of $\pm 5 \mathrm{~cm}$. River bathymetry is generally obtained by manual cross sections measurements just few weeks after or before the aerial flight, depending on flow and weather conditions. Cross sections along the river are measured on average every $20 \mathrm{~m}$. For each cross section, the profile of the river bed is obtained by measurements spaced every $50 \mathrm{~cm}$.

Cross section data are then merged with the DTM in order to obtain a new DEM which includes the river bathymetry. To this purpose we use the method developed by Schaeppi et al. (2010), which requires as inputs: (i) cross section profiles data, (ii) a raster of the DTM that needs to be corrected and (iii) the identification of breaklines (Lane et al., 1994; Keim, 1999; Brasington et al., 2000). The algorithm is designed to deal with longitudinal unequally spaced cross section profiles. It performs two linear interpolations in the lateral and longitudinal direction of the river. DTM grid points situated in between two adjacent cross section profiles are replaced by values obtained from the cross section interpolation. This method was chosen because it is more robust than the nonlinear ones and those based on spline interpolations,
Table 1. Nutrient content and soil type analysis results. Soil samples were dried at $40^{\circ} \mathrm{C}$, and then sieved at $2 \mathrm{~mm}$.

\begin{tabular}{llll}
\hline & Units & Mean & $\mathrm{SD}$ \\
\hline Sand & $\%$ & 81 & 5 \\
Silt + Clay & $\%$ & 19 & 4 \\
Organic carbon & $\mathrm{g} \mathrm{C} \mathrm{kg}^{1}$ soil & 9.2 & 3.2 \\
Total nitrogen & $\mathrm{g} \mathrm{N} \mathrm{kg}^{1}$ soil & 0.6 & 0.2 \\
Available phosphorus & $\mathrm{mg} \mathrm{k} \mathrm{kg}^{1}$ soil & 24.9 & 8.7 \\
\hline
\end{tabular}

which often introduce spurious oscillations due to not equally spaced data (Schaeppi et al., 2010).

\subsection{Terrestrial and aerial photography}

The high cost of aerial surveys makes them economically not feasible more than once a year. However, periodical extensive surveys are very important to monitor morphological changes and riparian vegetation patterns and evolution along rivers. Thus, we have decided to explore the possibility to replace periodical surveys by means of continuous monitoring through terrestrial photography. If successful, this technique may lead to promising applications in the field of river engineering and restoration. For instance, calibration of river hydrodynamic flow models is typically a difficult and demanding task, which requires adequate information about the corresponding water depth for different flow rates. The many points that are required across the river domain cannot be measured through manual survey, either because of excessive time demand or because of inherent difficulties in the presence of high flow conditions, which limit the access to the area. Remote survey techniques, for instance based on aerial photographs, are welcome.

To produce a continuous time series of aerial-like photographs we have installed two boxes (Fig. 3d) on the top of each monitoring tower at $16 \mathrm{~m}$ above the levee level. Each box contains two high resolution digital cameras shooting pictures in both the visible and the NIR range. By combining the visible and NIR images we can compute the Normalized Difference Vegetation Index (NDVI) (Qi et al., 1994), which is useful to quantify vegetation patterns, growth and mortality. All the digital cameras are connected to the remote computer, from which it is possible to change their shooting parameters and, in particular, the frequency, to better capture flood events evolution. Images from the tower have been complemented with photographs taken from a remotely controlled motorized paraglider (Fig. 3e), which has been equipped with the same type of high resolution digital camera and with a GPS for more convenient geo-referencing. The paraglider has been used to detect important morphologic changes, similar to what was shown by Lejot et al. (2007) soon after a flood occurred and without waiting for 
the annual airborne LIDAR flight. Using both image sets we have thus been able to test and improve several techniques based on pattern recognition analysis to calibrate both hydraulics and ecosystem models (Molnar et al., 2008; Perona et al., 2009a).

\subsection{Hydrodynamic simulation}

In order to characterize the hydrodynamics of the restored river reach under different flow scenarios we have used numerical simulations. The grid of the interpolated DTM (see Sect. 4.3) has been first pre-processed by means of the AQUAVEO SMS-10.1 software to create an unstructured triangular mesh, which is particularly suitable for fast and more efficient computing. For the hydrodynamic simulations we have used the 2-D hydrodynamic model BASEMENT (BAsic Simulation EnvironMENT). This open source software developed at the Laboratory of hydraulics, hydrology and glaciology of ETH Zurich (http://www.basement.ethz. ch) uses the finite volume method to integrate the shallow water equations. The explicit Euler scheme implemented deals both sub- and supercritical flow regimes, thus resulting a suitable code to perform hydrodynamic simulations across a broad range of natural streamflows (e.g., Ruf et al., 2008; Perona et al., 2008, 2009a,b).

\subsection{Experiments with vegetation cuttings}

The last element of the project investigations has concerned the understanding of the interaction between river hydrology and vegetation. This requires accurate monitoring of the vegetation growth dynamic and survival. In March 2008 we have started transplantations of vegetation cuttings, which have been selected among the indigenous species growing in the area (Verones, 2009). The campaign has been repeated in each year of the project and about 1200 cuttings of Salix Alba have been planted each year in early springtime. Cuttings have been organized in plots with different density, respectively 9 and 16 plants $\cdot \mathrm{m}^{-2}$, following the structure of a regular square matrix (see box in Fig. 5), in which cuttings are planted in correspondence of the nodes. Plots have been located all over the island (Fig. 5) with the purpose of testing the resistance of cuttings stressed by different drought and inundation conditions. In this respect the location of single plots has been decided also according to the shear stress patterns (Fig. 6) simulated by the numerical model discussed in Sect. 4.5. Within each consecutive year we have changed the location of the plots on the basis of the experience acquired during the preceding campaigns in order to validate previous observations or to increase the statistical significance of others. Periodic monitoring of the survival rates, of the main stem length and of the number of branches for each cutting has regularly been carried out every 15-30 days.

An accurate monitoring of the root-soil system has also been done in order to identify factors linking topological and

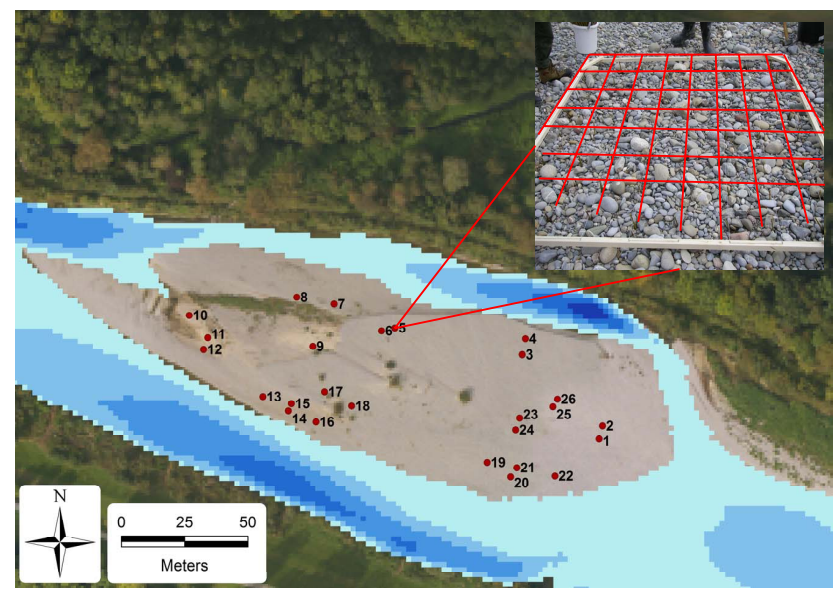

Fig. 5. Map of the investigated island showing the location of the vegetation plots in 2009. Plot location have been identified mainly according to hydraulic parameters (flow, shear stress and velocity) and to topography (elevation). The upper right corner box shows the matrix frame used for cutting plantation. One cutting is planted in the soil in correspondence of each node. We thus have a regular matrix which helps to identify cuttings positions during periodical surveys.

functional differences of root growth in relation to bar and island topography and hydraulic conditions as observed by other authors (Waisel et al., 2002). Cutting samples have been uprooted once a month at different plot locations and analyzed. For each plot, we have uprooted three cuttings by following a technique that aims at maintaining the highest level of integrity of the roots. Such technique consists of three steps: First, digging a deep trench about $1 \mathrm{~m}$ beside the cuttings, second, searching for the deepest point of the root system, third, gently removing the soil from the cutting and the root system to preserve the highest level of integrity of its three dimensional structure. The uprooted cuttings have been first washed to remove the excess particles of soil and organic material. Each cutting has been then separately layered down on a white paper to re-arrange it to the original 3-D structure that we have carefully reconstructed from pictures taken during uprooting. The picture which best returns the spatial distribution of the roots is further processed to obtain a gray scale image (Verones, 2009). By processing the gray-scale image using a filter to remove noise (due, for instance, to dust or fine soil particles) and a binary threshold that classifies pixels as 0 (black) and 1 (white), it has been possible to discriminate root segments from empty spaces. From the resulting binary matrix we have computed an empirical histogram of the root distribution (resulting from an average of three cuttings) with an appropriate number of classes.

Uprooted samples have been additionally processed to quantify their main morphological characteristics. For this purpose, roots have been first cut away from the primary root (i.e., the cutting, in this case, the size of which is 


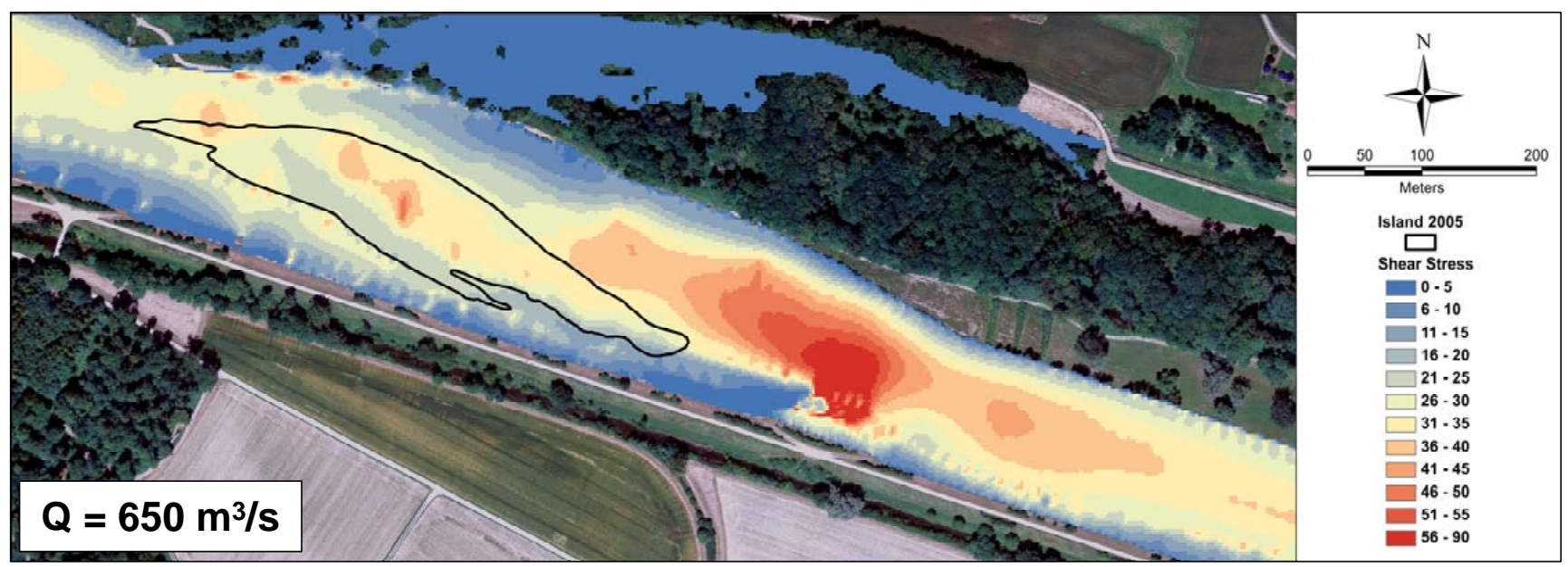

Fig. 6. Simulated bed shear stress produced by the maximum peak flow (corresponding to $650 \mathrm{~m}^{3} \mathrm{~s}^{-1}$ ) registered in the period $2005-2006$. Simulation of this type have been used to decide the location of Salix plots as well as for morphodynamic analysis. The shoreline of the island for $30 \mathrm{~m}^{3} \mathrm{~s}^{-1}$ for the 2005 topography is indicated in black.

measured by hand) and then spread in the water-filled transparent tray of a root scanner. The scanner - an EPSON Expression 10000XL - uses one light source from below as typical for common flat-bed scanners and a second, additional light transparent unit (TPU) from above. It is optimized extra for root images analysis by Regent Instrument, Inc. that also provides the processing software WinRhizo (Regent Instruments, 2009), which is appositely designed for detecting morphology, topology and architecture of root systems through the analysis of their images. The software returns the total root length, average root diameter, surface area, volume of the root system and number of tips and forks of the roots in the morphology package.

\section{Application examples and first results}

The experimental and modeling setup has been used to investigate the interaction among river hydraulic regime, vegetation establishment and its role in sediment anchoring, which, together, dictate the temporal dynamics of the river morphology. In particular we focused on flood magnitude, frequency and duration, as these are crucial parameters to understand plant growth and survival dynamics and their role in determining river morphodynamics. Whilst the return period of specific flow conditions can be estimated by flood frequency analysis, understanding spatial inundation patterns and consequent impacts on vegetation requires integrating multiple sources of information. We hereby illustrate how we have combined hydrodynamic simulations, terrestrial photography and vegetation cutting experiments to shed light on the problem of streamflow-sediment-vegetation dynamic interaction.

\subsection{Modeling of river hydraulics and morphodynamics}

A series of 2-D flow simulations at different flow rates for both the restored and the upstream straight reach have allowed to compute both the spatial and temporal variability of a number of flow related variables such as velocity components, water depth, water surface elevation, bed shear stress, etc. Throughout the remaining duration of the project we plan to perform additional flow simulations using different annual morphologies and flow conditions in order to establish a relationship between morphological and hydraulic variability and the related time dependency (see Sect. 6). This concept is well illustrated by Fig. 6, which shows the simulated bed shear stress for a flood peak of $650 \mathrm{~m}^{3} \mathrm{~s}^{-1}$ over the 2005 topography. The shoreline of the main island for a (low) flow rate of $30 \mathrm{~m}^{3} \mathrm{~s}^{-1}$ is drawn in black. The spatial distribution of the bed shear stress for varying flow conditions has allowed identifying the locations where critical conditions of incipient (bedload) sediment motion were first reached. Given the average grain size distribution curve of the surface sediment (see Sect. 4.2) with $d_{10}=4 \mathrm{~mm}, d_{30}=10 \mathrm{~mm}, d_{50}=20 \mathrm{~mm}, d_{70}=50 \mathrm{~mm}$ and $d_{90}=90 \mathrm{~mm}$, the classical Shield's theory (e.g., Meyer-Peter and Muller, 1948) predicts particles equal to $20 \mathrm{~mm}$ moving for flows equal or greater than $200 \mathrm{~m}^{3} \mathrm{~s}^{-1}$. For the simulated flow shown in Fig. 6 sediment material sized up to $d_{90}$ was practically completely mobilized from the highest stress region (red zones) to lower stress ones where sediment is eventually deposited according to local stress conditions. This picture would suggest a future of slow migration of the island toward the right-hand river side, i.e., according to the downstream migrating nature of alternate bars (Federici and Seminara, 2003). From the sequential analysis of successive morphologies over the next years we expect 

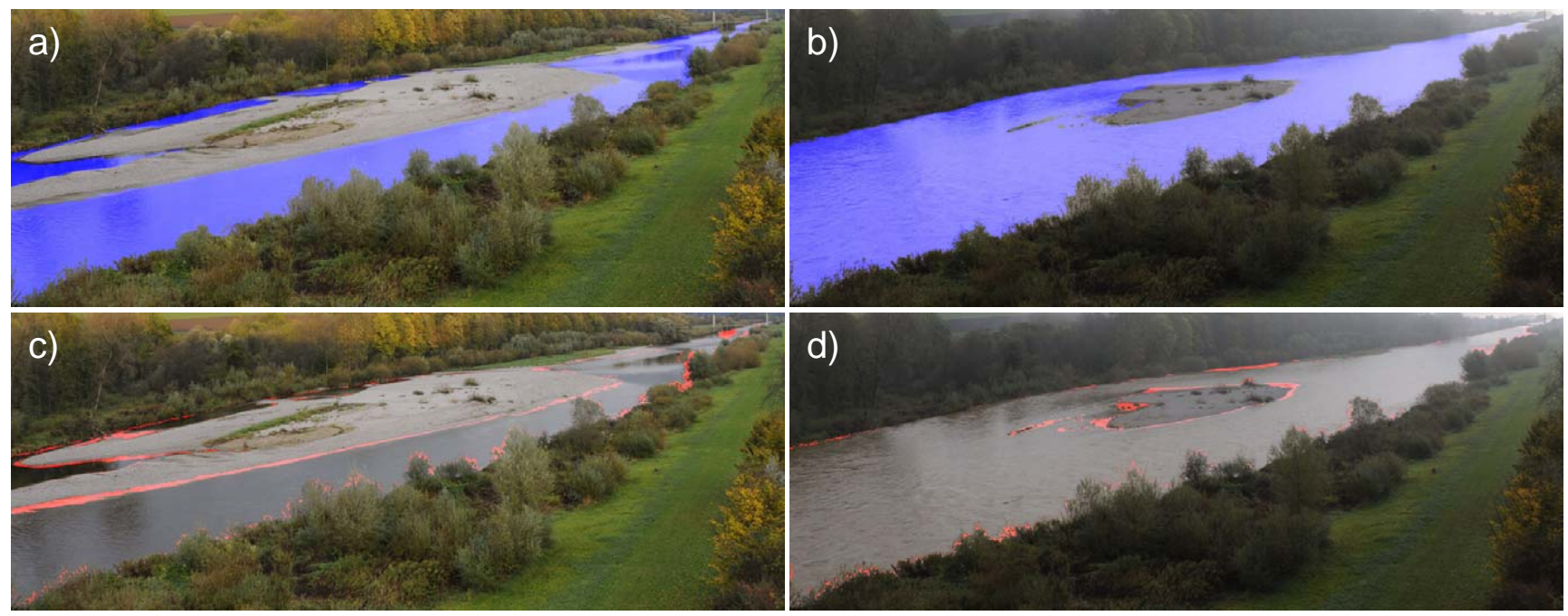

Fig. 7. Example of water and non-water classes recognition from digital photographs under changing light and surface albedo. Such conditions are typically due to either diurnal variability or bad weather conditions (e.g., like fog or snow). Pictures (a) and (c) show a low discharge case, whereas (b) and (d) show a high discharge. Blue is the detected water (a, b). Red are the classification errors (c, d).

to understand whether alternate "free" bars will gradually concentrate around the river bend, thus assuming a punctual character, eventually forced by the local river curvature (Tubino and Seminara, 1990), or the establishment of vegetation (either natural or planted throughout the project) will be able to influence, at least locally, the expected morphology. The observation of this evolution will have important implication as far as the stability of the lateral banks (e.g., the right-hand side one in this case) is concerned.

\subsection{Monitoring: use of terrestrial photography for pattern recognition and model calibration}

Matching model predicted river morphology with experimental evidence requires the availability of frequent and spatially distributed survey of the riverine landscape changes. This can be obtained with permanent terrestrial photography installations, which allow, in principle, automatic pattern recognition. Automatically recognizing patterns is relatively easy in the presence of well-defined objects and contrasting background colors, however this operation becomes rather difficult for open air or environmental photographs like those of river corridors - where a multitude of colors, shadows, reflections and changing light conditions typically characterize the images. Our installation is a natural laboratory in this respect and has allowed us to tackle the problem with specific reference to pattern recognition of river corridor elements (Fig. 7). For instance, we have approached the problem of recognizing water and non-water classes from digital photographs under changing light and surface albedo (e.g., due to either diurnal variability or bad weather conditions like the presence of fog or snow). When water can be removed, the exposed island surface can be computed and used for a variety of purposes.

The approach that we have followed consists first of masking the images by ignoring the irrelevant parts like mountains and sky, for instance. Next, features are defined to describe properties of the image or the image content, like, e.g., color values, gradients of neighboring pixels, or application specific information, like a probability distribution of a pixel being water-derived from the digital elevation model. The investigated features can be classified according to two orthogonal dimensions: (i) pixel based features and features derived from a group of pixels and (ii) time-variant (derived from a time series of images) and time-invariant features (derived from a single image). All the collected features are then used in a supervised learning algorithm, which calculates the probability that a specific pixel belongs to the water class.

The learning algorithm needs a training set of images to compute the relation between the feature space and the two classes, and to suggest how important a feature is for the classification. Time-variant features (such as color values of water due to changing light conditions) require continuous adaptation of the classifying algorithm to the most relevant selected feature in order to address the observation of highly variable condition/quality of the images and to adapt to local environment changes. The evaluation of the proposed approach has been done by classifying a test set having similar characteristics to the training set but being independent of it. The classification of water is in particular difficult in areas where vegetation is reflected in the water. To derive the time-variant characteristics of these pixels, the relevant areas are sampled continuously. Since these samples are based on a specific position in the in the image, the dislocation of the 
camera, due to wind or maintenance operations, affects the classification result negatively. Ideally a new initialization is required to determine new positions in the image for sampling. Figure 7 shows results of the learning process on two representative pictures at different discharges. If the training set of images is large enough, the error of the image processing is reasonable and comparable to any flow simulation numerical model. Given the promising results we plan to test this technique on a longer data record or on photographs from different locations in order to develop a non-invasive calibration technique for hydraulic models.

\subsection{Experiments: above-ground vegetation dynamics}

Quantitative observation of cuttings collected during monitoring campaigns together with aerial photographs have allowed quantifying vegetation plots growth (or mortality) rates in relation to the natural river hydrologic regime. Figure 8 shows a representative data set of four plots in 2009 . We define potential growth as the average cutting length of each plot computed by excluding the death ones and effective growth as the average cutting length of the whole including damaged, removed or died plants. This definition of growth average allows considering that a damaged biomass may indeed have single branches (i.e., cuttings in this case) growing at the effective rate despite the biomass has decreased. From Fig. 8 it is evident that plot 1 and plot 8 are located at high elevation on a portion of the island less frequently inundated. Accordingly, they have experienced a much lower velocity and shear stress intensity, so that their potential and effective growth has been practically monotonic. On the contrary, plot 19 , located at really low elevation, has been removed by the first big flood in June 2009. This is not surprising, as the location of this plot is characterized by much higher frequency and duration of inundation (it is inundated for all floods higher than $50 \mathrm{~m}^{3} \mathrm{~s}^{-1}$ ). Compared to such two extreme situations, plot 21 (located at intermediate elevation) shows that, on average, it survives the season despite some plants are either partially damaged or died due to main floods, in June and July 2009. It is worth to note that, after the first flood has affected the plot, the potential growth is always higher than the effective one. Thus, the more the two curves differ, the more the plots are expected to be located at lower and more flood risk prone elevations.

From visible and NIR pictures taken at the same time, we have computed the NDVI index (Defries and Townshend, 1994; Wu and Tang, 2010), the histogram of which allows identifying the amount of water (NDVI $<-0.3$ ), soil (NDVI $=-0.3: 0.1)$ and vegetation (NDVI $>-0.1$ ) on the island. An exemplary result, showing the variability of this index on a specific day illustrated in Fig. 9, supports the rationale for comparing different NDVI histograms throughout the season, in order to obtain an additional piece of quantitative information complementing that from field monitoring.

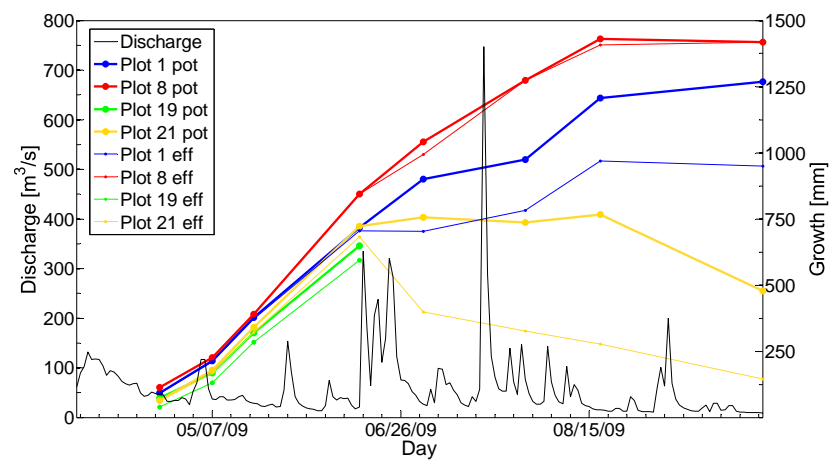

Fig. 8. Example of correlation between vegetation mortality and highly impulsive natural floods. Plot located at higher elevations ( 1 and 8$)$ are less frequently inundated and experience also less stresses during floods. Their growth is therefore almost linear and monotonic during the whole season. The effect of inundation is more evident on plot 21 sited at a lower elevation. In the period of the three consecutive peaks in June we register a negative growth for plot 21 (stems are broken). The same three floods cause the complete removal of all plot 19 cuttings, the one at the lowest elevation. Thicker lines represent the potential growth whereas thin lines are the effective growth. Effective growth is always smaller than the potential and shows more evidently flood effects.

\subsection{Experiments: root growth, anchoring and erosion dynamics}

Salix is rather sensitive to prolonged droughts, but at the same time it is able to withstand long periods of submergence (Glenz, 2005; Glenz et al., 2006). Since our plots are spread on the island, they may have experienced both situations depending on river hydrology. However, long periods of submergence may be associated with larger floods that can induce erosion and uprooting. For a given above-ground canopy, cutting resistance to floods will eventually depend on the root architecture, which in turn is also the result of river hydrology. Figure 10a shows the effect of a flood on a plot in 2009 , documenting the survival of the plot despite the deep scouring of sediments around the cutting, which has also partially exposed the roots. Although this picture reflects a situation quite often observed in natural systems, it is quite difficult to obtain in controlled experimental field campaigns. This partial erosion depicts the type II mechanism of rooted sediment erosion dynamics conceptualized by Edmaier et al. (2011) and suggests the nonlinear role that root architecture plays in locally stabilizing and anchoring the sediment.

While we recognize that more experimental observations are necessary to understand rooted sediment erosion dynamics, this first set of experiments has allowed us to carry out some preliminary investigation. First, we have investigated if the vertical root density distribution correlates with the statistical location of the saturated water table in the sediment. Because precipitation can be considered spatially homogeneous at the island scale, soil moisture changes in deep soil 

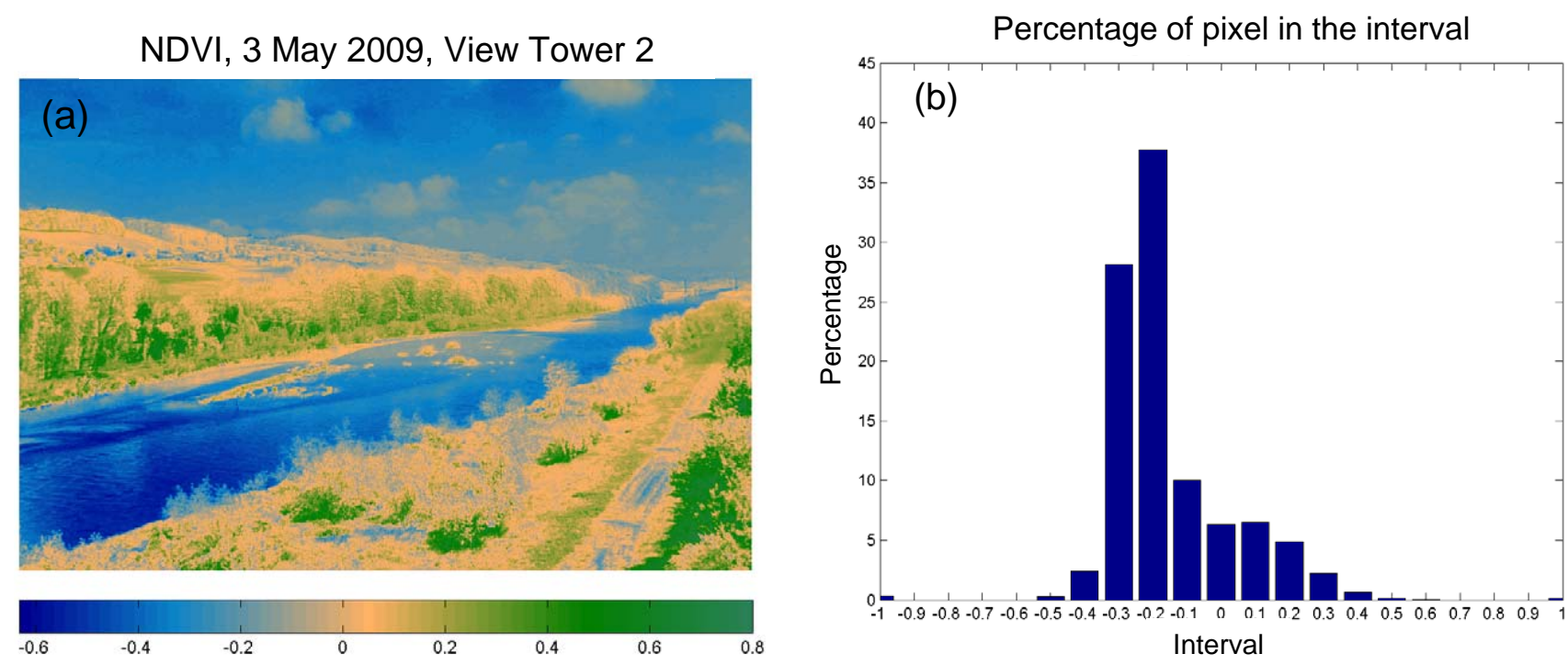

Fig. 9. NDVI picture of the field site (a) on 3 May 2009. Pixels with values between 0.1 and 0.8 correspond to vegetation cover, pixels ranging from -0.2 and 0.1 represents bare soil and values smaller than -0.2 denote water. Panel (b) shows the corresponding empirical distribution of the NDVI values of the image in (a).
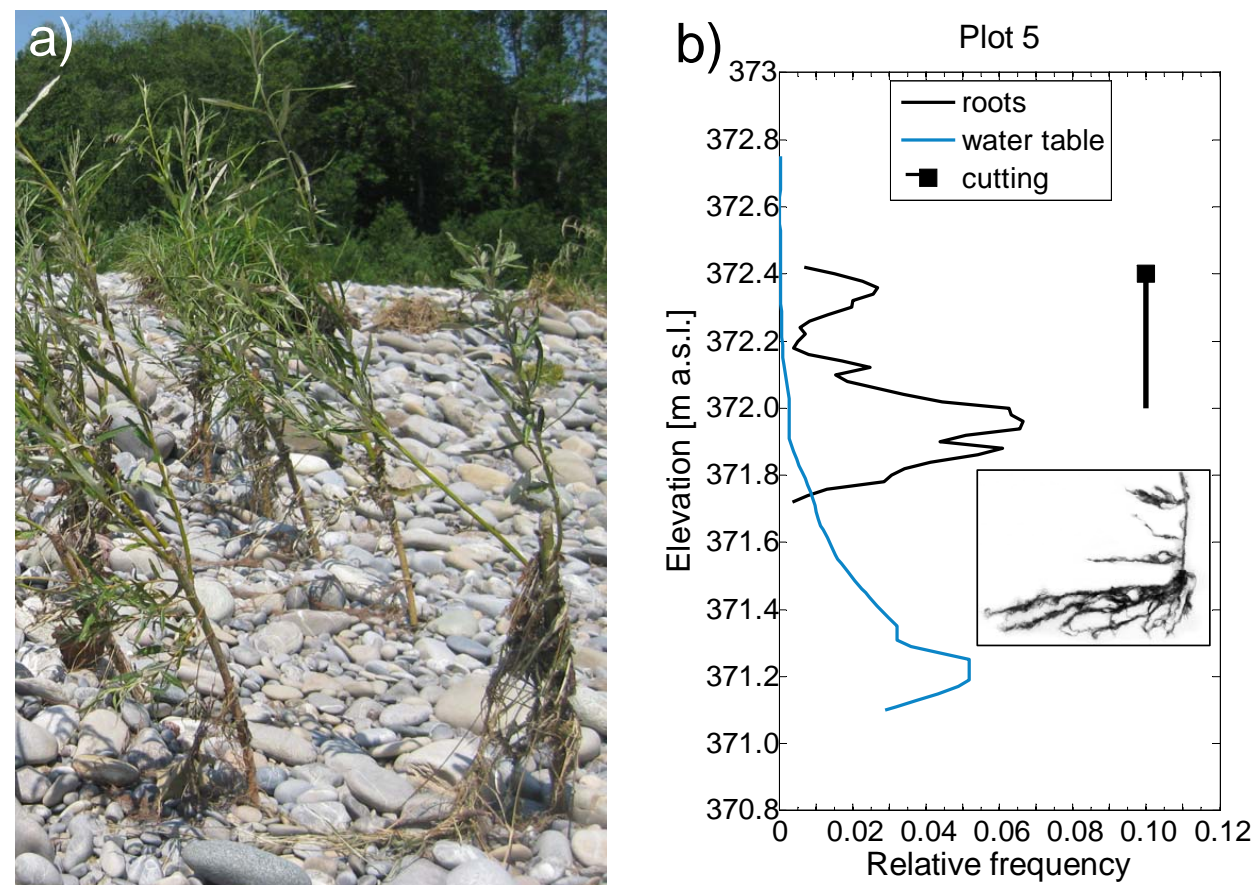

Fig. 10. Example of scouring produced during flood events with resulting exposure of the cutting roots (a). Panel (b) shows the distribution of the root density and of the water table for the same plot.

are likely dependent on streamflow statistics. Accordingly, we simulated by means of the hydraulic model mentioned in Sect. 5.1 the flow conditions ranging from the minimum recorded flow up to the maximum, which completely inundates the island. Given the coarse size distribution of the alluvial material and its high conductivity $\left(k=2 \times 10^{-2} \mathrm{~m} \mathrm{~s}^{-1}\right)$, we expect the vertical water front to infiltrate at a rate which is comparable to the hydrograph dynamics. Therefore, we have assumed the water table to propagate in quasi-steady state dynamics for common river hydrograph conditions. This has allowed us to obtain a "rating curve" of the saturated water table for all plots of the island, starting from the 

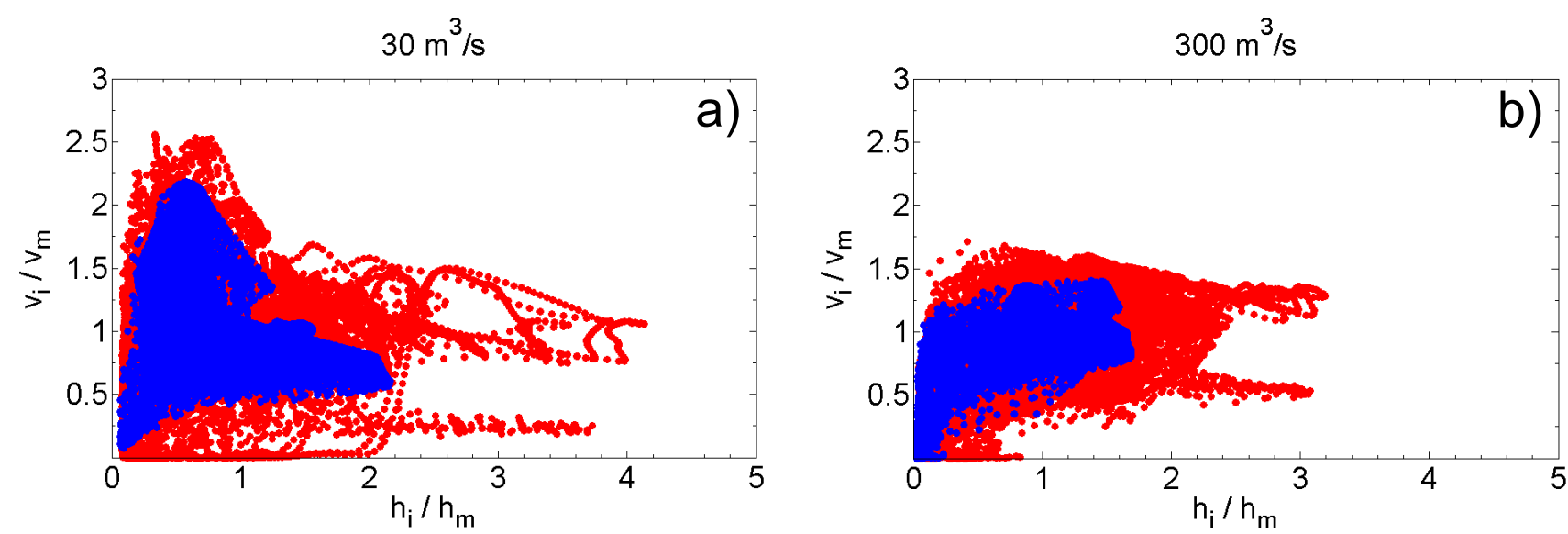

Fig. 11. State plane projection showing the spatial variability of the modeled hydraulic variables $(h, v)$ for the straight (blue) and the restored (red) reaches at two different flowrates (right).

water surface elevation in quasi-steady state conditions. This method is described in Schneider et al. (2011) together with its application in relation to groundwater issues.

Then, we have jointly analyzed the data obtained from analysis of cutting roots of regularly uprooted samples, together with the local water table simulated by the model. This has allowed us to document the location of the maximum root density in relation to the most frequent location of the saturated water table. Figure 10b, which summarizes this analysis for one exemplary plot, seems to indicate that the root distribution depends on the location on the island, and thus on the dynamics of the local water table. Although we recognize that such conclusion cannot be generalized and further analysis is needed in order to obtain comparable and statistically significant results, we are persuaded that specific regularities can be found. In particular, we speculate that a scaling relationship may exist, which predicts the depth at which cuttings are going to develop the highest root density as a function of the river hydraulic regime. If found, such relationship would have important implications on using vegetation as natural engineer in restoration projects. Further experiments on many additional plots sparsely located on the island are currently ongoing with the purpose of validating our conjecture and searching for a suitable mechanistic rule of root development in relation to river hydrology in alluvial sediment.

\section{Concluding remarks}

Hydrological indicators of river restoration efficacy are often based on flow variables such as flow depth, velocity, shore line length, exposed area, wet perimeter and their gradients under variable flow conditions, because they are well correlated with ecological indicators (Emery et al., 2003; Clifford et al., 2005). A high spatial variability of these variables indicates areas with high habitat diversity (e.g., Lamouroux et al., 1992; Allan and Castillo, 2007). Thus, empirical approaches have been proposed in the literature to relate the form and shape of velocity and depth distributions to predictor variables that are relatively easy to determine (Lamouroux, 1995, 1998). However, these approaches show some limitations to comprehensively describe the degree of spatial variability, especially with respect to temporal dynamics that are generated by disturbances, such as flood events, which contribute substantially to rework the river morphology. As far as the Thur River is concerned, an example can be made by plotting modeled flow velocities vs water depth for both the restored and the upstream straight reaches (e.g., Schweizer, 2007; Schweizer et al., 2007). An example of such variability is shown in Fig. 11, which illustrates the dimensionless modeled flow velocities versus the dimensionless water depths, which we have simulated for both the restored and the original (straight) Thur river reach using the 2005 topography. The higher spread of points simulated for the restored reach than for the straight one under low flow conditions points to the variability in velocity and depth produced by restoration. This is a fundamental factor regulating ecosystems (Allan and Castillo, 2007), which strongly influences, e.g., benthic plants, invertebrates as well as fishes (Quinn and Hickey, 1994; Bovee, 1982; Jowett, 2003). Figure 11 is also consistent with Stewardson's hypothesis (Stewardson and McMahon, 2002), which suggests the existence of two fundamental bivariate distributions of water depth and velocity. One is characterized by a centered form with a positive correlation resulting from significant cross-channel effects and weak along-channel effects whereas the other is characterized by a skewed shape resulting from longitudinal bed undulations (e.g., pool-riffle sequences) and minimal lateral variation. Increasing the discharge produces a shift from a positively skewed (Fig. 11a) to a symmetric (Fig. 11b) distribution. At higher flow rate more and more fluvial forms are submerged, and the similarity between the restored and the 
non-restored reaches, as expected, increases. The description of the framework of experimental activities, as well as the related instrumentation setup, data analysis and simulations implemented within the RECORD project, has shown that quantifying the evolution of a restored river reach is possible if a coordinated effort is undertaken. In this respect, we provided in this paper a vision for a modern and comprehensive approach to monitor the trajectory of morphodynamic evolution after restoration on the basis of a mechanistic understanding of the main acting dynamic processes, which can be exported to other river contexts. We expect that this approach will be able to identify whether the restored system will evolve toward a multi-thread system implying levee and bank erosion, or will develop along a (naturally) limited evolution to a constant width river reach characterized by a system of alternate bar forming, migrating and disappearing. In the case of the Thur River our preliminary observations seem to indicate that the second case is more likely taking place. Further investigations are currently ongoing to better explore the role that vegetation (and in particular the above and the below ground biomass) may have in controlling the morphodynamic and hydrogeomorphic changes of this river and, more in general, of rivers that, though restored, are still constrained by artificial boundaries.

Acknowledgements. This study was funded by the Competence Center Environment and Sustainability (CCES) of the ETH domain in the framework of the RECORD project (Assessment and Modeling of Coupled Ecological and Hydrological Dynamics in the Restored Corridor of a River - REstored CORridor Dynamics - http://www.cces.ethz.ch/projects/nature/Record). We thank Romeo Favero, Ulrich Guettelmann, Robert Holzschuh, Andreas Scholtis, and Marco Baumann from "Amt fur Umwelt" of Canton Thurgau and Urs Spychiger, Franz Bieler, Kurt Nyfenegger, and Matthias Oplatka from AWEL, Canton Zurich for their support and close cooperation. Thanks also to Francesca Casini and Thomy Keller for helping with the grain size curve analysis and Sander Nouta for assistence with pattern analysis.

Edited by: E. Durisch-Kaiser

\section{References}

Allan, D. J. and Castillo, M. M.: Stream Ecology: Structure and Function of Running Waters, vol. 125, Kluver Academic, Boston, 2nd edition, doi:10.1577/1548-8659-125.1.154, 2007.

Ashworth, P. J., Ferguson, R. I., and Powell, M. D.: Bedload transport and sorting in braided channels, in: Dynamics of gravel-bed rivers, edited by: Billi, P., Hey, R. D., Thorne, C. R., and Tacconi, P., John Wiley \& Sons LTD, Hoboken, NJ, USA, 497-515, 1992.

Battle-Aguilar, J., Brovelli, A., Luster, J., Shrestha, J., and Barry, D. A.: Carbon and nitrogen dynamics in a variably saturated soil profile, Model application to a restored Swiss riparian area, in preparation, 2011.
Bovee, K. D.: A guide to stream habitat analysis using the in.stream flow incremental methodology, Fish And Wildlife Services, Fort Collins, CO, US, 1982.

Brasington, J., Rumsby, B. T., and McVey, R. A.: Monitoring and modelling morphological change in a braided gravel-bed river using high resolution GPS-based survey, Earth Surf. Proc. Land., 25, 973-990, 2000.

Brookes, A.: Channelized rivers: Prospectives for Environmental Management, John Wiley \& Sons LTD, Hoboken, NJ, USA, 344 pp., 1988.

Cairns, J.: The status of the theoretical and applied science of restoration ecology, The Environmental Professional, 13, 186194, 1991.

Clifford, N. J., Soar, P. J., Harmar, O. P., Gurnell, A. M., Petts, G. E., and Emery, J. C.: Assessment of hydrodynamic simulation results for eco-hydraulic and eco-hydrological applications: a spatial semivariance approach, Hydrol. Process., 19, 3631-3648, doi:10.1002/hyp.5855, 2005.

Colombini, M., Seminara, G., and Tubino, M.: Finite-amplitude alternate bars, J. Fluid Mech., 181, 213-232, 1987.

Defries, R. S. and Townshend, J. R.: NDVI derived land-cover classifications at global-scale, Policy, 15, 3567-3586, 1994.

Densmore, R. V. and Karle, K. F.: Flood Effects on an Alaskan Stream Restoration Project: The Value of Long-Term Monitoring, J. Am. Water Resour. Assoc., 45, 1424-1433, doi:10.1111/j.1752-1688.2009.00373.x, 2009.

Diplas, P. and Parker, G.: Deposition and removal of fines in gravelbed streams, in: Dynamic of gravel-bed rivers, edited by: Billi, P., Hey, R. D., Thorne, C. R., and Tacconi, P., John Wiley \& Sons LTD, Hoboken, NJ, USA, 313-329, 1992.

Edmaier, K., Burlando, P., and Perona, P.: Mechanisms of vegetation uprooting by flow in alluvial non-cohesive sediment, Hydrol. Earth Syst. Sci. Discuss., 8, 1365-1398, doi:10.5194/hessd8-1365-2011, 2011.

Emery, J. C., Gurnell, A. M., Clifford, N. J., Petts, G. E., Morrissey, I. P., and Soar, P. J.: Classifying the hydraulic performance of riffle-pool bedforms for habitat assessment and river rehabilitation design, River Res. Appl., 19, 533-549, doi:10.1002/rra.744, 2003.

Federici, B. and Seminara, G.: On the convective nature of bar instability, J. Fluid Mech., 487, 125-145, doi:10.1017/S0022112003004737, 2003.

Fitter, H.: An Architectural Approach to the Comparative Ecology of Plant Root Systems, New Phytol., 106, 61-77, 1987.

Formann, E., Habersack, H., and Schober, S.: Morphodynamic river processes and techniques for assessment channel evolution in Alpine gravel bed rivers, Geomorphology, 90, 340-355, doi:10.1016/j.geomorph.2006.10.029, 2007

Gee, G. W. and Bauder, J. W.: Methods of Soil Analysis, Part I, Agron. Monogr. 9, ASA and SSSA, Madison, WI, USA, 2nd edition, 1986.

Gilvear, D., Francis, R., Willby, N., and Gurnell, A.: Gravel bars: a key habitat of gravel-bed rivers for vegetation, in: Process Understanding to River Restoration, edited by: Habersack, H., Piègay, H., and Rinaldi, M., Elsevier, ISSN: 0928-2025, 2025, 677-700, 2008.

Glenz, C.: Riparian forest dynamics in central Europe - Tool for decision-making in river restoration, Ph.D. thesis, 2005. 
Glenz, C., Schlaepfer, R., Iorgulescu, I., and Kienast, F.: Flooding tolerance of Central European tree and shrub species, Forest Ecol. Manag., 235, 1-13, doi:10.1016/j.foreco.2006.05.065, 2006.

Gurnell, A. and Petts, G.: Trees as riparian engineers: The Tagliamento River, Italy, Earth Surf. Proc. Land., 31, 1558-1574, 2006.

Ikeda, S., Parker, G., and Sawai, K.: Bend theory of river meanders, Part 1. Linear development, J. Fluid Mech., 112, 363-377, 1981.

Inglis, C. C.: The behaviour and control of rivers and canals (with the aid of models), Central Water Power, Irrigation and Navigation Research Station, Poona, India, Research pubblication 13 part 1, 1949.

Jang, C. L. and Shimizu, Y.: Vegetation effects on the morphological behavior of alluvial channels, J. Hydraul. Res., 45, 763-772, doi:10.1080/00221686.2007.9521814, 2007.

Jowett, I. G.: Hydraulic constraints on habitat suitability for benthic invertebrates in gravel-bed rivers, River Res. Appl., 19, 495-507, doi:10.1002/rra.734, 2003.

Keim, R.: Digital terrain modeling of small stream channels with a total-station theodolite, Adv. Water Resour., 23, 41-48, doi:10.1016/S0309-1708(99)00007-X, 1999.

Kuo, S.: Phosphorus, in: Methods of soil analysis: Part 3 - chemical methods, edited by: Sparks, D. L., SSSA, Madison, WI, USA, 1996.

Lacey, G.: Stable channel in alluvium, Proceedings of the institution of civil engineers, 229, 259-292, 1930.

Lamouroux, N.: Predicting velocity frequency distributions in stream reaches, Water Resources, 31, 2367-2375, 1995.

Lamouroux, N.: Depth Probability Distributions in Stream Reaches, J. Hydraul. Eng., 124, 224-227, doi:10.1061/(ASCE)0733-9429(1998)124:2(224), 1998.

Lamouroux, N., Statzner, B., Fuchs, U., Kohmann, F., and Schmedtje, U.: An unconventional approach to modeling the spatial and temporal variability of local shear stress in stream segments, Water Resour. Res., 28, 3251-3258, doi:10.1080/07900629208722560, 1992.

Lane, S. N., Richards, K. S., and Chandler, J. H.: Developments in monitoring and modelling small-scale river bed topography, Earth Surf. Proc. Land., 19, 349-368, doi:10.1002/esp.3290190406, 1994.

Lanzoni, S.: Experiments on bar formation in a straight flume 2. Graded sediment, Water Resources, 36, 3351-3363, 2000.

Lejot, J., Delacourt, C., Piégay, H., Fournier, T., Trémélo, M.L., and Allemand, P.: Very high spatial resolution imagery for channel bathymetry and topography from an unmanned mapping controlled platform, Earth Surf. Proc. Land., 32, 1705-1725, doi:10.1002/esp.1595, 2007.

Leopold, B. L. and Wolman, M. G.: River Chanel Patterns: Braided, Meandering and Straight, United States Government Printing Office, Washington, 1957.

Lisle, T. E. and Madej, M. A.: Spatial variation in armoring in a channel with high sediment supply, in: Dynamics of gravel-bed rivers, edited by: Billi, P., Hey, R. D., Thorne, C. R., and Tacconi, P., John Wiley \& Sons LTD, Hoboken, NJ, USA, 277-293, 1992.

Lisle, T. E., Ikeda, H., and Iseya, F.: Formation of stationary alternate bars in a steep channel with mixed-size sediment - A flume experiment, Earth Surf. Proc. Land., 16, 463-469, 1991.
Malmqvist, B. and Rundle, S.: Threats to the running water ecosystems of the world, Environ. Conserv., 29, 134-153, doi:10.1017/S0376892902000097, 2002.

Meyer-Peter, E. and Muller, R.: Formulas for bed-load transport, Proceedings of the 2nd Meeting of the International Association for Hydraulic Structures Research, 39-64, 1948.

Millar, R. G.: Influence of bank vegetation on alluvial channel patterns, Water Resour. Res., 36, 1109, doi:10.1029/1999WR900346, 2000.

Mitsch, W.: Ecological engineering: A field whose time has come, Ecol. Eng., 20, 363-377, doi:10.1016/j.ecoleng.2003.05.001, 2003.

Molnar, P., Favre, V., Perona, P., Burlando, P., Randin, C., and Wolfgang, R.: Floodplain forest dynamics in hydrologically altered mountain river, Peckiana, 5, 17-24, 2008.

Nat, D. V. D., Schmidt, A. P., Tockner, K., Edwards, P. J., and Ward, J. V.: Inundation Dynamics in Braided Floodplains : Tagliamento River, Northeast Italy, Ecosystems, 5, 636-647, doi:10.1007/s10021-002-0170-0, 2002.

Olde Venterink, H., Vermaat, J. E., Pronk, M., Wiegman, F., van der Lee, G. E. M., van den Hoorn, M. W., Higler, L., and Verhoeven, J. T. A.: Importance of sediment deposition and denitrification for nutrient retention in floodplain wetlands, Appl. Veg. Sci. 9, 163-174, 2006.

Palmer, A. M., Moenninger, L. H., and Bernhardt, E.: River restoration, habitat heterogeneity and biodiversity: a failure of theory or practice?, Freshwater Biol., 55(Suppl. 1), 205-222, doi:10.1111/j.1365-2427.2009.02372.x, 2010.

Perona, P., Molnar, P., Savina, M., and Burlando, P.: Stochastic sediment - vegetation dynamics in an Alpine braided river, IAHS Publ., 325, 266-274, 2008.

Perona, P., Camporeale, C., Perucca, E., Savina, M., Molnar, P., Burlando, P., and Ridolfi, L.: Modelling river and riparian vegetation interactions and related importance for sustainable ecosystem management, Aquat. Sci., 71, 266-278, doi:10.1007/s00027-009-9215-1, 2009a.

Perona, P., Molnar, P., Savina, M., and Burlando, P.: An observation-based stochastic model for sediment and vegetation dynamics in the floodplain of an Alpine braided river, Water Resour. Res., 45, 1-13, doi:10.1029/2008WR007550, $2009 \mathrm{~b}$.

Peter, A., Kienast, F., and Woolsey, S.: A strategy to assess river restoration success, Archives de Science, 15, 643-656, 2006.

Pollen, N.: Temporal and spatial variability in root reinforcement of streambanks : Accounting for soil shear strength and moisture, Catena, 69, 197-205, doi:10.1016/j.catena.2006.05.004, 2007.

Pollen, N. and Simon, A.: Estimating the mechanical effects of riparian vegetation on stream bank stability using a fiber bundle model, Water Resoures, 41, 1-11, doi:10.1029/2004WR003801, 2005.

Qi, J., Chehbouni, A., Huete, A. R., Kerr, Y. H., and Sorooshian, S.: A Modified Soil Adjusted Vegetation Index, Remote Sens. Environ., 126, 119-126, 1994.

Quinn, J. M. and Hickey, C. W.: Hydraulic parameters and benthic invertebrate distributions in two gravel-bed New Zealand rivers, Freshwater Biol., 32, 489-500, doi:10.1111/j.13652427.1994.tb01142.x, 1994.

Rodhe, S.: River restoration: potentials and limitations to re-establish riparian landscapes. Assestment and planning, Ph.D. thesis, ETH Zurich, 2004. 
Ruf, W., Foglia, L., Perona, P., Molnar, P., Faeh, R., and Burlando, P.: Modelling the interaction between groundwater and river flow in an active alpine floodplain ecosystem, Peckiana, 5, 5-16, 2008.

Samaritani, E., Shrestha, J., Fournier, B., Frossard, E., Gillet, F., Guenat, C., Niklaus, P. A., Tockner, K., Mitchell, E. A. D., and Luster, J.: Heterogeneity of soil carbon pools and fluxes in a channelized and a restored floodplain section (Thur River, Switzerland), Hydrol. Earth Syst. Sci. Discuss., 8, 1059-1091, doi:10.5194/hessd-8-1059-2011, 2011.

Schaeppi, B., Perona, P., Schneider, P., and Burlando, P.: Integrating river cross section measurements with Digital Terrain Models for improved flow modelling applications, Comput. Geosciences, 36(6), 707-716, 2010.

Schirmer, M., Luster, J., Linde, N., Perona, P., Mitchell, E., Barry, D. A., Cirpka, O. A., Schneider, P., Vogt, T., Tockner, K., Burlando, P., Pannatier, E. G., Green, A., Hoehn, E., Hollender, J., Kipfer, R., and Durisch-Kaiser, E.: River restoration: Morphological, hydrological, and ecological changes and challenges, in preparation, 2011.

Schneider, P., Vogt, T., Schirmer, M., Doetsch, J. A., Linde, N., Pasquale, N., Perona, P., and Cirpka, O. A.: Towards improved instrumentation for assessing river-groundwater interactions in a restored river corridor, Hydrol. Earth Syst. Sci. Discuss., 8, 2503-2553, doi:10.5194/hessd-8-2503-2011, 2011.

Schweizer, S. P.: Predicting the consequences fo river rehabilitation measures on morphology, hydraulics, pheriphyton and on invertebrates Zürich, Switzerland 2007, Ph.D. thesis, 2007.

Schweizer, S. P., Borsuk, M. E., and Reichert, P.: Predicting joint frequency distributions of depth and velocity for instream habitat assessment, River Res. Appl., 23, 287-302, doi:10.1002/rra.980, 2007.

Soar, P. J. and Thorne, C. R.: Channel restoration design for mendering rivers, US Army Engineer Research and Development Center, Vicksburg, Miss., 2001.
Steiger, J. and Gurnell, A, M.: Spatial hydrogeomorphological influences on sediment and nutrient deposition in riparian zones: observations from the Garonne River, France, Geomorphology, 49, 1-23, doi:10.1016/S0169-555X(02)00144-7, 2003.

Stewardson, M. J. and McMahon, T. A.: A stochastic model of hydraulic variations within stream channels, Water Resour. Res., 38(1), 1007 doi:10.1029/2000WR000014, 2002.

Tockner, K. and Stanford, J.: Riverine flood plains: present state and future trends, Environ. Conserv., 29, 308-330, doi:10.1017/S037689290200022X, 2002.

Trush, W. J., McBain, S. M., and Leopold, L. B.: Attributes of an alluvial river and their relation to water policy and management, P. Natl. Acad. Sci. USA, 97, 11858-11863, 2000.

Tubino, M. and Seminara, G.: Free-forced interactions in developing meanders and suppression of free bars, J. Fluid Mech., 214, 131-159, 1990.

Verones, F.: Experiments on Salix shoot and root growth on river alluvial sediment with programming for image analysis, Master thesis, ETH, Zurich, 2009.

Waisel, Y., Eshel, A., and Kafkafy, U.: Plant roots: The hidden half, 3rd edition, Marcel Dekker, NY, 2002.

Walthert, L., Graf, U., Kammer, A., Luster, J., Pezzotta, D., Zimmermann, S., and Hagedorn, F.: Determination of organic and inorganic carbon, $\delta^{13} \mathrm{C}$, and nitrogen in soils containing carbonates after acid fumigation with $\mathrm{HCl}$, J. Plant Nutr. Soil Sci., 173, 207-216, doi:10.1002/jpln.200900158, 2010.

Wohl, E., Angermeier, P. L., Bledsoe, B., Kondolf, G. M., Macdonnell, L., Merritt, D. M., Palmer, M. A., Poff, N. L., and Tarboton, D.: River restoration, Water Resources, 41, 1-12, doi:10.1029/2005WR003985, 2005.

Woolsey, S., Capelli, F., Gonser, T. O. M., Hoehn, E., Hostmann, M., Junker, B., Paetzold, A., Roulier, C., Schweizer, S., Tiegs, S. D., Tockner, K., Weber, C., and Peter, A.: A strategy to assess river restoration success, Freshwater Biol., 52, 752-769, doi:10.1111/j.1365-2427.2007.01740.x, 2007.

Wu, J. and Tang, A. D.: The influence of water conveyances on restoration of vegetation to the lower reaches of Tarim River, Environ. Earth Sci., 59, 967-975, 2010. 